\title{
Take this book and shelve it!
}

\author{
By Paul Heller and Stuart Kohler
}

\section{An interactive instruction program for student shelvers}

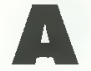
cademic libraries rely increasingly on student assistants (often participants in the federally subsidized work-study program) for everything from stack maintenance to basic reference services. At Norwich University in Vermont as many as 60 new employees must be trained annually.

Training students, who may only work as few as six hours a week, is labor intensive and exhausting for supervisors. Because of their class schedules they are seldom available in large groups. Consequently, each student worker must be trained individually. This has usually been done by means of a tutorial-a one-on-one session where library staff invest considerable time in basic instruction of rudimentary library concepts. It is not unusual to make a significant investment of staff time in the training of a worker who may never again show for a work assignment.

Typically, our new student workers are assigned stack maintenance responsibilities-shelving and shelf-reading comprise the greater portion of their time in the library and their performance is, naturally, directly related to the ability of our patrons to find materials in the stacks. A book that is misshelved is, for practical purposes, inaccessible to library users, even though its status is indicated as available in our library's OPAC. Further compromising this situation is the difficulty of quality control. It is extremely inefficient to ensure shelving accuracy by spot-checking or other follow-up procedures. It is far more productive to instill basic stack-maintenance concepts with a training program that does not require burdensome tutorials for regular library staff.

"Take This Book and ShelveIt!" is an interactive instructional program for student shelvers developed at Norwich University's Kreitzberg Library by Stuart Kohler. The program covers a basic introduction to call numbers (both Dewey Decimal and Library of Congress) and then presents an interactive exercise sorting "virtual books" on a "virtual shelf." The screens shown here are examples from the Windows version (there is also a "Shelvelt!" for Macs).

The introductory screen offers three options: a student worker can get an overview of the

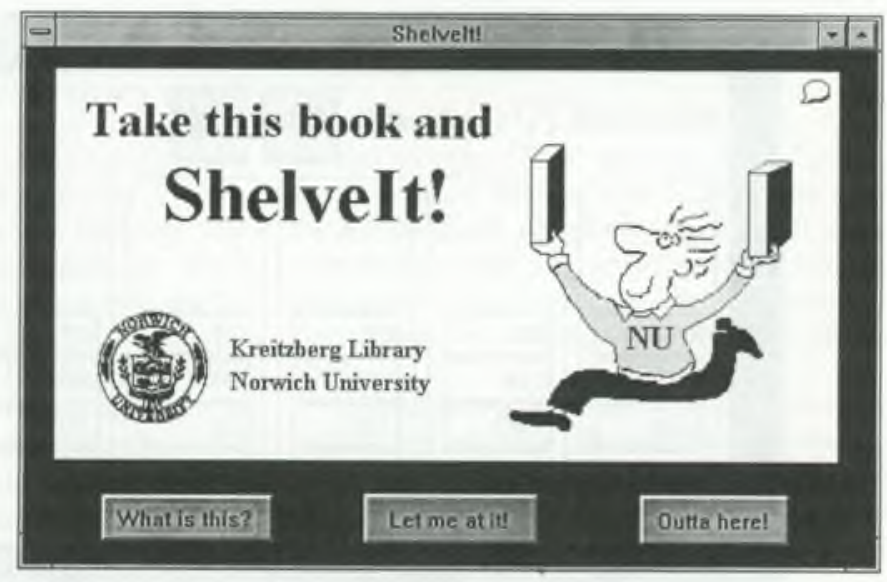

Paul Heller is director of libraries at Norwich University in Northfield, Vermont, e-mail: paul@nomvich.edu; Stuant Kobler is information tecbnology librarian at Norwich, e-mail: stuartk@nonwich.edu 


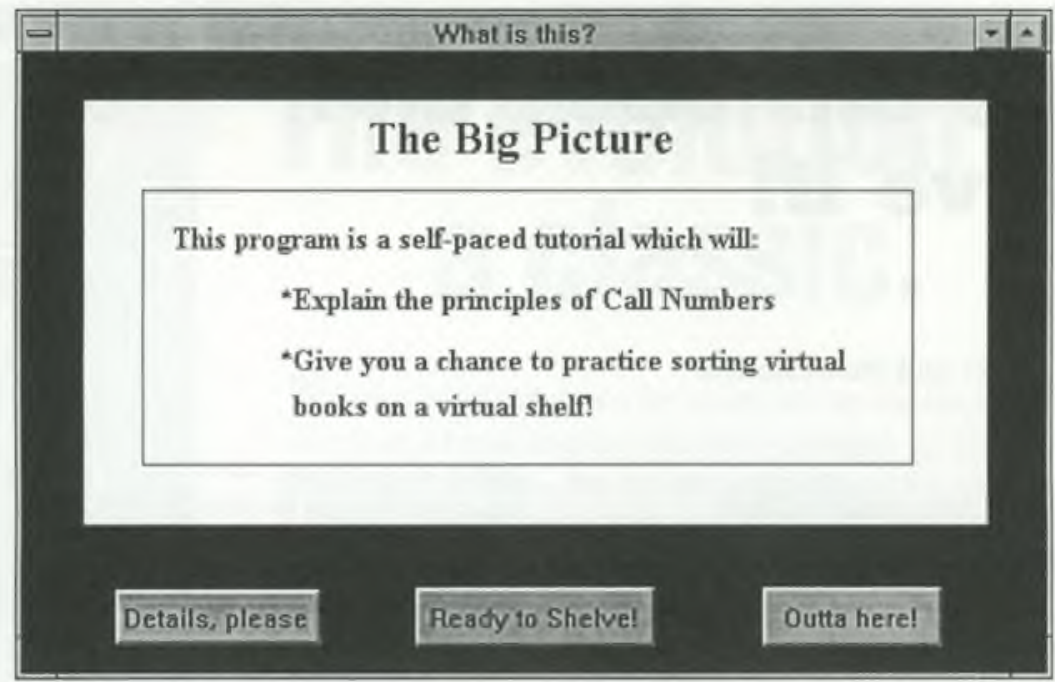

tutorial, an explanation of why accurate shelving is important, and explanations of basic concepts.

The student is then presented with the virtual bookshelf and may click on a book and then an arrow to arrange the call numbers in correct order. After arranging the books to his or her satisfaction a click on "Check Me!" will reveal the accuracy of the order.

After five correct repetitions the user is congratulated for five consecutive successes, then reports to the stack supervisor for a brief introduction to the collection, and turned loose with a book truck. Anecdotal experience confirms that our student shelvers are more reliable and our spot inventories reveal fewer shelving errors. Clearly, our stack supervisor has found relief from the tedious task of training 60 new faces a year, and she is convinced that our shelvers' knowledge and attention to detail is greater than before.

"Take This Book and Shelvelt!" is shareware available at the Norwich Library's Web site. For the Windows or Mac version, point your browser at www.norwich.edu/library/fonul/ shelveit.htm.

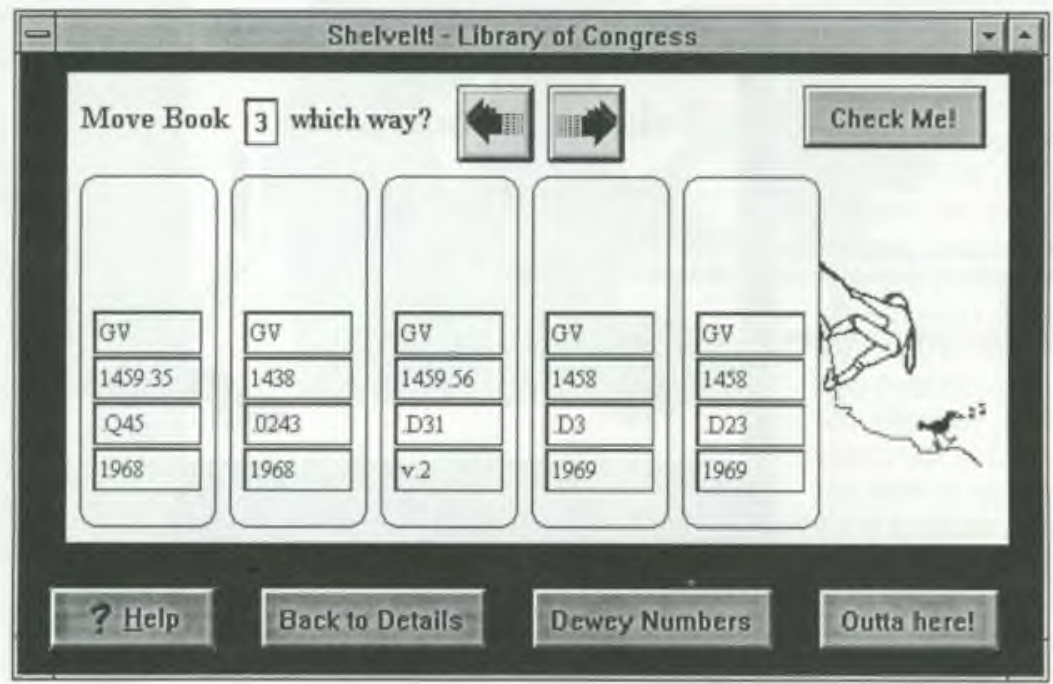

